\title{
Correction to: Inshore migration of a tropical eel, Anguilla marmorata, from Taiwanese and Japanese coasts
}

\author{
Takaomi Arai $^{1,4} \cdot$ Miho Marui $^{2} \cdot$ Tsuguo Otake $^{3} \cdot$ Katsumi Tsukamoto $^{2}$
}

Published online: 17 January 2022

(c) Japanese Society of Fisheries Science 2022

\section{Correction to: Fisheries Science (2002) 68:152-157 https://doi.org/10.1046/j.1444-2906.2002. 00401.x}

In this article, the bottom figure (total length $49.8 \mathrm{~mm}$ in Japan) in Fig. 2 was corrected.

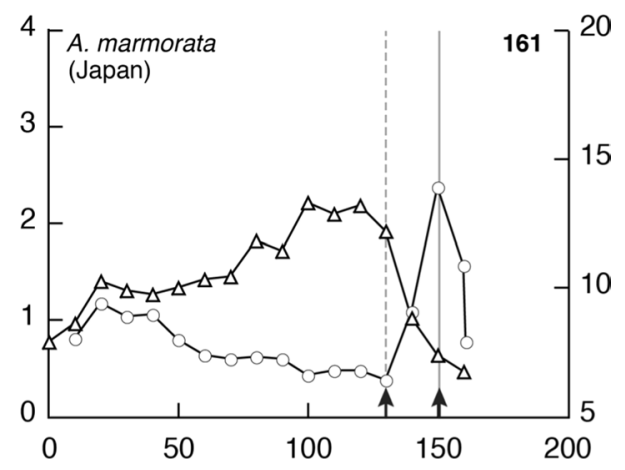

The profile is shown as a representative specimen to examine the early life history characteristics of Anguilla marmorata. Therefore, the authors consider that this does not influence the main results, discussion and conclusions in this study.

The original article can be found online at https://doi.org/10. 1046/j.1444-2906.2002.00401.x.

Takaomi Arai

takaomi.arai@ubd.edu.bn

1 Otsuchi Marine Research Center, Ocean Research Institute, The University of Tokyo, Otsuchi, Iwate 028-1102, Japan

2 Ocean Research Institute, The University of Tokyo, Nakano, Tokyo 164-8639, Japan

3 Faculty of Bioresources, Mie University, Kamihama, Tsu 514-8507, Japan

4 Present Address: Faculty of Science, Universiti Brunei Darussalam, Jalan Tungku Link, Gadong BE1410,

Brunei Darussalam
Publisher's Note Springer Nature remains neutral with regard to jurisdictional claims in published maps and institutional affiliations. 